\title{
Nietzsche e a Historiografia Prussiana: análise de fragmentos póstumos da Primeira Fase de sua obra
}

\author{
Nietzsche face to Prussian Historiography: analysis offragments \\ posthumous of the first phase of your work \\ Celso Kraemer ${ }^{1}$ \\ Dominique Santos ${ }^{2}$ \\ Aniele Crescêncio ${ }^{3}$
}

Ao observar as relações de Nietzsche com seus contemporâneos verifica-se que ele estava ciente das principais discussões relativas à Unificação da Alemanha (1871). Para a unificação era necessário que os 39 estados alemães compartilhassem o sentimento de pertencimento a uma pátria comum. Nesse meandro, os historiadores prussianos do século XIX desempenharam papel fundamental ao produzir um ambiente filosófico nacionalista, uma maneira científica e objetiva de pensar sobre a história. O objetivo deste trabalho é compreender as interações de Nietzsche com estes círculos intelectuais. Para isto, foram selecionados quatro dos chamados fragmentos póstumos de Nietzsche datados entre 1871 e 1873. De acordo com o ponto de vista de Nietzsche, as pretensões dos historiadores não tinham nenhuma crítica, pois acreditavam, ingenuamente, que a verdade era um alvo tangível. Por outro lado, ele indicou a necessidade de uma história ligada à cultura, que era trabalhada em conjunto com "instintos artísticos".

Palavras chave: Historiografia. Século XIX. Nietzsche. Teoria da História.

\section{ABSTRACT}

By observing the relationship of Nietzsche with his contemporaries one can notice that he was aware of the main discussions related to the unification of Germany (1871). Unification required 39 German states to share the feeling of belonging to a common homeland. Prussian historians of the nineteenth century played a key role in producing such a nationalist philosophical environment, a scientific and objectivist way of thinking about History. This work aim is to understand the interactions between Nietzsche and this intelectual circles. For this purpose, four of the so-called posthumous Nietzsche fragments, dated between 1871

\footnotetext{
${ }^{1}$ Fundação Regional de Blumenau-FURB-SC

${ }^{2}$ Fundação Regional de Blumenau-FURB-SC

${ }^{3}$ Universidade Federal de Ouro Preto-UFOP
} 
and 1873, were selected. According to Nietzsche's point of view, some historians had a naive pretension to reach the truth, as if it were a tangible target. On another hand, he pointed out the necessity of a link between History and Culture, which should be understood altogether with 'artistic instincts'.

Keyword: Historiography. 19th century. Nietzsche. Theory of History.

\section{Introdução}

As discussões acerca da escrita da história não são apenas importantes para a historiografia contemporânea. O tema já era amplamente debatido na Prússia do século XIX, por exemplo, a partir de um movimento que hoje denominamos "historicismo alemão". Um dos intelectuais do período que se interessou pela temática foi Friedrich Wilhelm Nietzsche. Durante sua trajetória, ele dissertou acerca da arte, filosofia, história, moral, política, religião e outras inumeráveis questões. Devido às suas reflexões sobre história, ele se tornou uma referência importante para a área.

Analisando as discussões sobre o pensamento de Nietzsche para a reflexão historiográfica, percebe-se que, pelo menos em grande parte das publicações brasileiras, o que se tem priorizado é sua Segunda Consideração Intempestiva: Da utilidade e desvantagem da história para a vida, por ser este seu maior escrito dedicado a pensar a história. No entanto, as visões de Nietzsche acerca da história não podem ser reduzidas a este escrito, pois ele também aborda o tema em outros momentos de sua trajetória, como podemos perceber a partir de seus vários fragmentos póstumos. O objetivo deste trabalho é compreender as percepções de Nietzshe sobre a história, em sua primeira fase, a partir de quatro destes fragmentos póstumos. Acreditamos que este corpus documental pode fornecer uma compreensão mais abrangente da visão do filósofo acerca desta.

Os fragmentos que analisamos se encontram no livro intitulado Escritos sobre História (NIETZSCHE, 2005) obra organizado por Noéli Correia de Melo Sobrinho. Trata-se de uma tradução para o português brasileiro, de parte das obras de Nietzsche, sistematizadas por Giorgio Colli e Mazzino Montinari. O livro é dividido em três partes, na primeira, encontra-se o texto de Nietzsche Fatum e História; na segunda parte, a Segunda Consideração Intempestiva;

e na terceira parte fragmentos póstumos e aforismos, divididos em seis itens. É o quarto item, denominado $A$ objetividade e a cientificidade da história, da última parte do livro, que nos interessa e dentre os 34 fragmentos que ali aparecem estão os quatro trechos que selecionamos. Fornecemos, em nota de rodapé, os fragmentos na língua alemã, de forma que o leitor possa os acompanhar também no idioma no qual foram escritos. 


\section{Breves considerações sobre a trajetória de Nietzsche}

Nietzsche estava interessado em discussões que perpassavam seu cotidiano. Neste sentido, é importante considerar aspectos de sua vida. Acreditamos, assim, poder sistematizar melhor os debates presentes em suas obras.

Ele nasceu em 15 de outubro de 1844, na Prússia. Aos 5 anos perdeu o pai e o irmão. Com isso, ele, sua mãe e sua irmã mudaram-se para Namburg, onde ingressou em um internato, o Colégio Real de Pforta. Quando formado, frequentou a Universidade de Bonn (MARTON, 1993, p.22-23). Nesta, estudou simultaneamente teologia e filologia, mas "conquistado pelas aulas do padre Ritschl, reserva sua atenção apenas para a filologia" (GRANIER, 2011, p.10). Em 1865, quando Ritschl transferiu-se para Leipzig, Nietzsche resolveu mudar-se também, "no entanto, o interesse de Nietzsche se dirige cada vez mais para a filosofia" (GRANIER, 2011, p.11), o que aconteceu após ler $O$ mundo como Vontade e Representação, de Arthur Schopenhauer (SAFRANSKY, 2011, p.37). Já na cidade, Nietzsche fundou, com Ritschl, a Sociedade Filológica de Leipzig, e publicou artigos sobre esta área (MARTON, 1993, p.23). É esta universidade que "lhe concede o título de doutor em filologia, mesmo sem ele ter defendido uma tese, com base na qualidade de seus trabalhos publicados" (GIACÓIA JUNIOR, 2000, p.83). No ano de 1868, Nietzsche conheceu Richard Wagner, algo que parece ter sido decisivo para sua trajetória intelectual, pois "este primeiro encontro lhe causa fortíssima impressão, que contribui, em contraste, para aumentar sua aversão ao meio filológico" (GRANIER, 2011, p.12). Nietzsche afastou-se de Wagner em 1876, por motivos como sua "submissão ao mercado", "ideais do cristianismo" e "pretenções estreitamente nacionalistas do Império Alemão" (GIACÓIA JUNIOR, 2000, p.85). O ano de 1868 foi muito especial para a carreira de Nietzsche, pois foi quando o professor Ritschl o recomendou ao cargo de professor na Universidade de Basiléia. Assim, Nietzsche se transferiu para a Suíça (GRANIER, 2011, p.12), onde atuou como professor de filologia clássica (MARTON, 1993, p.24).

Mesmo que a formação de Nietzsche tenha sido em filologia, hoje ele é internacionalmente reconhecido como filósofo. Isto acontece, pois, o seu mérito não é proveniente de sua formação em si, são as suas obras que evidenciam este caráter, bem como o seu afastamento da filologia, já mencionado acima. Em seu período na universidade da Basileia, Nietzsche estabeleceu estreitas relações com o historiador Jacob Burckhardt e o teólogo Franz Overbeck. Com o passar dos anos, Burckhardt "se afastará do discípulo por desaprovar a audácia de suas idéias". Mas Overbeck, no entanto, foi um grande amigo de Nietzsche até o fim de sua vida (MARTON, 1993, p.24-25).

No ano de 1879, dores intermináveis de cabeça e na vista o fazem pedir demissão da universidade, da qual recebe uma pensão que utilizará como sustento até falecer (MARTON, 1993, p.30). Sem suas obrigações acadêmicas, seguiu a vida viajando pela Europa. Foi em uma viagem que fez a convite de Malwida von Meysenbug e Paul Rée, amigos que conheceu 
respectivamente nos anos de 1872 e 1873 (MARTON, 1993, p.27), que foi apresentado a Lou Andreas-Salomé. Sua relação com Salomé foi intensa e conflitante. Tanto Nietzsche quanto seu amigo Rée se interessaram por esta jovem russa. Nietzsche propôs casamento a ela, mas não teve sucesso neste quesito. Com a proposta recusada, o trio, que ambicionava morar em um mesmo local para trabalhar e estudar muda de ideia e Lou e Rée desistem de morar com Nietzsche para morarem juntos, em Berlim, o que faz o filósofo se sentir traído (SAFRANSKY, 2011, p. 227-234).

O estado de saúde de Nietzsche piorou progressivamente. Peter Gast ${ }^{1}$ chegou a ler para ele em voz alta e fazer-lhe transcrições (MARTON, 1993, p.36). Entre 1888 e 1889, Nietzsche começou a escrever "bilhetes com diversas assinaturas" e, logo depois, entrou em tensão psíquica². Franz Overbeck o levou à Suíça, onde foi internado em uma clínica psiquiátrica. Em 1890, sua mãe o buscou e ele ficou aos cuidados dela e da irmã até falecer em Weimar, no ano de 1900. Não há consenso sobre a enfermidade de Nietzsche. Há indícios que pode ter sido hereditária, pode ter sido causada pelo abuso de drogas, ou sífilis (MARTON, 1993, p.38-39).

\section{A divisão da obra de Nietzsche em fases}

A divisão da obra de um autor de destaque geralmente é um trabalho póstumo de seus estudiosos. Muitas vezes, embora sempre guarde algumas polêmicas sobre a legitimidade de tal "divisão", ela é motivada por características da própria obra, outras para facilitar didaticamente a referência a conceitos ou usos específicos de conceitos pelo autor ou seus estudiosos. A título de exemplo temos Immanuel Kant e suas fases "pré-Crítica", "Crítica" e "pós-Crítica”; Karl Marx, em "Jovem" e "Velho" Marx; Michel Foucault as fases "Arqueológica”, "Genealógica" e "Ética”, de modo que Nietzsche também tem suas obras divididas em fases.

Scarlett Marton indica que há variações a respeito da divisão do percurso da obra de Nietzsche em períodos; Charles Andler e Raoul Richter, por exemplo, dividem sua obra em duas fases; Karl Löwith, por sua vez, adota a divisão em três períodos; Carl-Albrecht Bernouilli considera $O$ Nascimento da Tragédia um livro à parte e determina quatro períodos para a obra de Nietzsche (MARTON, 1990, p.24). Ruth Abbey (2000, p.xii) afirma que a divisão em três períodos foi elaborada por Lou Salomé, raramente lembrada por isto. Porém, para Marton (1990, p.24), o próprio Nietzsche teria sugerido esta divisão em uma carta a Overbeck em 2 de fevereiro de 1883, na qual ele afirma que sua vida a cada seis anos dá um passo. Tomando este trecho de Nietzsche como referência, a autora divide os escritos do filósofo nos seguintes períodos: 1864 a 1870; 1870 a 1876; 1876 a 1882; 1882 a 1888. Esta divisão é difundida entre os estudiosos de Nietzsche, apesar de ignorarem a primeira etapa, segundo Marton, por consistir de anotações,

${ }^{1}$ Amigo que conheceu em 1875 e tem como nome verdadeiro Heinrich Köselitz.

${ }^{2}$ Nietzsche, por exemplo, envia algumas cartas em janeiro de 1889 assinando como "Dyonisos" e "Der Gekreuzigte", o crucificado. Certamente se referindo a Jesus Cristo. Disponíveis em: http://www.nietzschesource.org/\#eKGWB/BVN1889,1255a. Acesso em: 20 set. 2015. 
poemas, notas autobiográficas, etc. Ou seja, nesta divisão considera-se apenas os três últimos períodos da produção intelectual do filósofo, sendo primeira (1870-1876), segunda (1876-1882) e terceira fase (1882-1888). Este artigo detém-se a aspectos específicos da primeira fase, segundo essa divisão.

Sobre a primeira fase Giacóia Junior afirma que:

Sua obra inicial é marcada por um interesse pronunciado pela estética, assim como pela intervenção crítica no debate cultural e político alemão [...] percebese ainda a forte influência sobre Nietzsche dos românticos alemães, assim como Arthur Schopenhauer e Richard Wagner.(GIACÓIA JUNIOR, 2013, p.75-76)

No ano de 1872 Nietzsche publicou seu primeiro livro, O Nascimento da Tragédia no Espírito da Música. Neste, há grande influência do filósofo Arthur Schopenhauer e do compositor Richard Wagner. Após os ataques de Willamowitz-Möllendorf ao livro, Nietzsche perde alunos, diminui muito a procura às aulas que ministrava (MARTON, 1993, p.26-27). É deste período também, do ano de 1974, sua Segunda Consideração Intempestiva.

Estabelecidas rapidamente estas considerações acerca da divisão da obra nietzscheana, resta buscar alguma compreensão de aspectos da Prússia do século em que Nietzsche viveu, pois a construção de um argumento histórico plausível requer consideração contextual. Compreendendo-se o tempo e lugar específicos em que o filósofo construiu suas ideias possibilita compreendê-las em sua genealogia, ou seja, "da ação das forças no processo histórico. Uma utilidade atual denota apenas uma apropriação que ocorre numa cadeia de apropriações e que produz sempre novas utilidades" (PASCHOAL, 2005, p. 76).-

\section{A Prússia do século XIX}

Nietzsche pertenceu a um território em constantes "guerras de unificação sob liderança da Prússia [...] muitos historiadores viram-se integrados no esforço de construção do novo Estado" (BENTIVOGLIO, 2010, p.36). Os intelectuais mencionados aqui estão ligados a uma região específica da atual Alemanha. Assim, "prussianos" é um termo mais adequado ao período que "alemães" para se referir a eles.

A Prússia da segunda metade do século XIX produziu muitas reflexões sobre a história. Foram, em grande medida, os historiadores, a partir de narrativas políticas, que impulsionaram e legitimaram a Unificação da Alemanha (1871). Neste período, surgiu a necessidade da escrita de uma história comum a todos os Estados envolvidos da unificação. O processo de unificação, capitaneado pelo Reino da Prússia (BENTIVOGLIO, 2010, p.26), não envolveu só historiadores, mas outros intelectuais, inclusive Nietzsche.

Segundo Bentivoglio, são os acontecimentos que se desenvolveram desde o início do século XIX, especificamente a partir do ano 1806, que permitem compreender o contexto da 
unificação. Este período se situa entre "a derrota fragorosa em Iena para Napoleão Bonaparte e a vitória sobre a França e anexação dos territórios de Alsácia e Lorena por Otto von Bismarck" (BENTIVOGLIO, 2010, p.26), importantes para a fundação do Império Germânico e, consequentemente, a emergência do nacionalismo.

O marco para a disseminação do império foi quando Napoleão obrigou a criação da Confederação do Reno, com a intenção de criar "uma terceira Alemanha para neutralizar a Áustria e à Prússia", esta confederação foi criada a partir de procedimentos franceses e era de interesse da Prússia fortalecer seu Estado para poder libertar os outros do domínio francês, "essas reformas e a luta contra a França iriam assentar as bases do poder prussiano no novo século e resultar na formação de uma nova Alemanha em 1871". (KITCHEN, 2013, p.19).

Após o domínio napoleônico, surgiu, nos estados alemães, um grande ódio aos franceses, com um resquício de nacionalidade marcado por "peculiaridades culturais e linguísticas do mundo de língua alemã. Era abstrata, humana, cosmopolita, filosoficamente refinada e apolítica" (KITCHEN, 2013, p.19-20). Diferente da Alemanha, "poderosa e unida", que era esperada pelos nacionalistas, o que aconteceu no Congresso de Viena (1914-1915) foi o surgimento da Confederação Alemã, compreendida pelos 39 estados remanescentes.

No ano de 1848, os alemães, em uma atitude revolucionária, se reuniram em Frankfurt para questionar sua identidade. Para a defesa de fronteiras "a maioria dos delegados do parlamento prussiano desejava uma solução alemã que incluísse a Áustria” (KITCHEN, 2013, p.20-21). O autor afirma que poucas pessoas, entre elas Nietzsche, se deram conta dos perigos da unificação nacional efetuada por meios tão violentos.

Sobre a visão do filósofo acerca de seu meio, dentre as principais ideias que nos auxiliam na compreensão deste período, e que é simpática a Nietzsche, é a noção de cultura. Norbert Elias, em sua obra Os Alemães (1997), entende a "história da cultura" ${ }^{3}$ como uma das duas categorias de análise que perpassam e predominam no século XIX. Elias afirma que, até o século XVIII, o conceito cultura tinha como significado a transformação da natureza pelo homem. A partir de então "o termo representou a imagem que faziam de si mesmos tal como a viam, ou seja, dentro de um contexto mais amplo do desenvolvimento da humanidade" (ELIAS, 1997, p.119). Para o historiador, este conceito e o de civilização, intensamente relacionados, vão perdendo seus significados generalizadores e sendo aplicados com mais especificidade. Os dois conceitos são, segundo Elias, lemas para uma nova perspectiva da história. Ele afirma ainda que há uma outra categoria de análise, iniciada por Voltaire, oposta à de "história da cultura" e que ajuda a compreendê-la. Trata-se da "história política".

A história política "colocava no centro da atenção os feitos de príncipes e cortesãos, os conflitos e alianças entre Estados, as ações de diplomatas e dos grandes chefes militares, em suma, a história dos setores aristocráticos dominantes e Estados absolutista." (ELIAS,

\footnotetext{
${ }^{3}$ Algo que requer cuidado no uso, pois não podemos traduzir o termo apenas como "cultura" e nem confundi-lo com as discussões do campo que, no Brasil, chamamos de "História Cultural". Esta História Cultural, que é francesa e não alemã, surge com força no Brasil na década de 1980 e está diretamente ligada aos conceitos de "identidade" e "representação".
} 
1997, p.121). A diferença era tão acentuada nos séculos XVIII e XIX que: "pode-se dizer que no significado do termo alemão 'Kultur' estava embutida uma pré-disposição não-política, e talvez mesmo antipolítica". Um dos escritores que contribuiu com debates acerca do assunto foi Jacob Burckhardt, com sua obra $A$ civilização da Renascença na Itália (ELIAS, 1997, p.122).

Entre os dois conceitos, Nietzsche simpatizava com a história da cultura, compreendida conforme as observações que fizemos. Em suas obras, o filósofo defende meios culturais como a arte, a dança e a música. Conforme Thomas Brobjer, "o principal interesse de Nietzsche não era a convencional história política, mas a história cultural e a história da filosofia" (BROBJER, 2004, p.312) ${ }^{4}$. A abordagem do conceito de civilização, extremamente vinculado ao de cultura naquele momento, por exemplo, por Burckhardt, é outro sintoma de que Nietzsche defendia a história da cultura. Além disso, na Segunda Consideração Intempestiva, sua crítica aos historiadores, que tendenciavam escrever sobre os grandes nomes, vai na mesma direção, pois, segundo Nietzsche, estes deveriam se preocupar com uma Historie für das Leben (história para a vida).

Nietzsche contribuiu muito para o debate acerca de várias temáticas relevantes ao contexto de construção de uma pátria alemã com costumes e pensamentos partilhados. Sem dúvida, suas interpretações acerca do conhecimento histórico, bem como suas interpretações acerca da utilidade da história, possuem vínculos com este período, pois estavam em conflito com a Escola Rankeana e Escola Histórica Prussiana. Este período foi, ao mesmo tempo, turbulento e de reconstrução, unificação e formação da Alemanha.

\section{Historicismo na Prússia do século XIX}

Atualmente, em História, trabalha-se com a noção de veracidade, o historiador tem que produzir enunciados de verdade e manter um compromisso ético com esta, embora saiba que esta não será atingida em sua totalidade. A comunidade científica em geral, é ciente, a partir de Kant, que a coisa em si não pode ser conhecida sendo, então, conhecedora do papel que a narrativa exerce no discurso historiográfico. Assim, a teoria da história, em suas discussões mais recentes, tem trabalhado com a plausibilidade, ou seja, ela "estipula as condições de produção de conhecimento histórico verossímil e as condições de inserção desse conhecimento em um leve arcabouço científico, plausível e convincente" (MARTINS, 2009, p.7). Assim, o único gênero de verdade aceito pela ciência contemporânea da História é a "verdade com certeza provável" (MARTINS, 2009, p.24). Estas questões são muito importantes para compreendermos o que os historiadores convencionaram denominar de historicismo, corrente com enorme força na historiografia prussiana do século XIX e que propôs inúmeras reflexões para a Ciência da História de maneira geral.

${ }^{4}$ Tradução nossa de: “[ ] Nietzsche's main interest was not conventional political history but cultural history and the history of philosophy [ ]" 
No século XIX, o conceito de História reivindicava a possibilidade de um discurso verdadeiro. As filosofias da história, influenciadas pelo movimento iluminista, anteriormente eram predominantes. Porém, no século XIX, passam a ser questionadas e começam a entrar em descrédito, o que não impediu que novas filosofias da história ainda fossem cunhadas por alguns autores, como, por exemplo, Hegel e Marx. Porém, o questionamento sobre elas culminou na noção de que há histórias e não somente uma história cosmopolita, linear e com sentido teleológico. Esta nova perspectiva teve grande influência no movimento que conhecemos atualmente como historicismo alemão.

Günter Scholtz (2013) afirma que já na segunda metade do século XVIII havia inúmeros escritos históricos preocupados com vários aspectos da cultura. Uma das obras de enorme importância no período foi a Scienza Nuova (1725) de Giambattista Vico. O movimento histórico do século XIX pensou amplamente questões sobre a fonte documental e os procedimentos fundamentais para o ofício do historiador. É importante abordá-lo, pois, como veremos as opiniões, idéias, críticas e intervenções de Nietzsche estavam profundamente vinculadas com as questões que eram consideradas pelos historiadores que participavam destes círculos intelectuais prussianos que fomentaram o aparecimento do historicismo.

O termo aparece em várias épocas, com múltiplas facetas, como podemos perceber a partir de Arno Wehling (1994). O autor também demonstra os diversos pontos de vista implícitos ao conceito e aponta as várias divisões do historicismo, como as caracterizadas por Meinecke, Sérgio Pistone, Mandelbaum e Iggers. Por fim, ele sugere a sua, que consiste em dividí-lo em três etapas: o Historicismo filosófico, o Historicismo romântico e o Historicismo cientificista. O caráter multifacetado do historicismo também está presente nas análises de Sérgio da Mata (2008) e Scholtz (2011).

A complexidade do historicismo não se limita a sua divisão temporal. Dentro do historicismo oitocentista, Julio Bentivoglio identifica diferentes escolas, "das quais se destacaram de um lado Ranke e seus seguidores e de outro a Escola Histórica Prussiana” (BENTIVOGLIO, 2010, p.21). Esta última, Bentivoglio vincula à revista de história Historische Zeitschrift.

Sobre os integrantes da Escola Histórica Prussiana, Bentivoglio apresenta suas características: "De um modo geral rejeitavam a filosofia da história de Hegel, a teoria da lei natural, a primazia do indivíduo - em seu lugar colocaram as forças históricas [...]. Acreditavam no progresso. E entendiam que o poder não é somente força, mas também um principio ético." (BENTIVOGLIO, 2010, p.39). Para esta revista, composta de 273 historiadores, foram enviados 783 artigos, a Historische Zeitschrift contou com “[...] três gerações de historiadores: a primeira composta por membros como Ranke, Waitz, Gervinus e Droysen; uma segunda composta por Sybel, Mommsen, Duncker e Häusser; e, a última, composta pela geração de Treitschke, Oncken, Waschsmut e outros" (BENTIVOGLIO, 2010, p.40). Nesta última geração há "um afastamento bem maior do paradigma rankeano". Mesmo levando em consideração que Ranke também participou da revista, é possível que seu pensamento seja considerado à parte não somente por causa do afastamento com seus ideais na terceira geração, mas por suas discordâncias com o 
caráter ideológico de outros membros da revista, como, por exemplo, Johann Gustav Droysen.

A historiografia deste período muitas vezes é apressadamente reduzida de forma depreciativa à obra de Leopold von Ranke. A fama de Ranke existe, em grande medida, por causa de uma expressão presente no seguinte fragmento:

À história foi atribuída a função de julgar o passado, de instruir os homens a tirar o melhor proveito dos anos por vir. A tentativa atual não tem tamanha pretensão. Ela aspira meramente a mostrar como as coisas efetivamente aconteceram (RANKE apud RÜSEN, 2011, p.131).

A expressão, wie es eigentlich gewesen (mostrar como as coisas efetivamente aconteceram), foi, por muito tempo, excluída de seu contexto, o que remetia à interpretações de que Ranke, ou até o historicismo, quando reduzido a este autor, tinha mero caráter de narrar a fonte de forma descritiva. Porém, quando Ranke escrevia tais palavras, estava preocupado, segundo Rüsen, com a crítica ao discurso moralista pré-moderno e a defesa do discurso moderno que tem como intenção abordar "a relação entre os historiadores e a experiência do passado, dada no material das fontes" (RÜSEN, 2011, p.130).

Boa parte das críticas feitas a Ranke constituem-se de um mito historiográfico. Ranke é pouco, ou nada, lido e as abordagens sobre ele são descontextualizadas, tanto textualmente quanto historicamente, o que faz da historiografia do XIX uma "historiografia positiva", legitimando uma suposta "revolução" dos Annales (MATA, 2010, 187-188).

Ranke, somado a 272 historiadores, estava diretamente envolvido na Historische Zeitzschrift (BENTIVOGLIO, 2010, p.40), debatendo, participando e partilhando das ideias do que hoje denominamos historicismo alemão. Todos estes intelectuais escreviam para este periódico, liam mutuamente as obras publicadas, opinavam sobre os textos uns dos outros, nem sempre em harmonia, e participavam deste movimento intelectual. Nietzsche, provavelmente, era leitor tanto de Ranke quanto de Droysen, bem como de alguns dos demais intelectuais que participavam da revista.

É importante compreender que as críticas de Nietzsche ao historicismo não se direcionam exclusivamente aos intelectuais que citamos acima. Segundo Giacóia Junior ${ }^{5}$ o tipo de historicismo criticado por Nietzsche, na Segunda Consideração Intempestiva,

formava então o Zeitgeist (espírito do tempo) sob cuja aurora desapontou o século XX, tanto em sua vertentes idealista inglesa, francesa, alemã (por exemplo, Berkley, Comte, Hegel, Eduard von Hartmann), quanto na materialista (por exemplo, Arthur Schopenhauer e a esquerda hegeliana). (GIACÓIA JUNIOR, 2013, p.86. Grifos nossos).

\footnotetext{
${ }^{5}$ Giacóia Junior (2013), ao tratar da crítica de Nietzsche ao "historicismo", tem como base a Segunda Intempestiva (1874), sendo que o mesmo afirma que a partir de Humano demasiado Humano (1878-1880) há certa emancipação intelectual de Nietzsche, o que pode modificar a visão de Nietzsche sobre o tema.
} 
Scarlett Marton também demonstra a oposição de Nietzsche "ao historicismo, de que tanto se orgulha o século XIX marcado pelo hegelianismo" e o "opõe o modelo grego" (MARTON, 2014, p. 37). Concordamos com Giacóia Júnior e Marton quando ambos se referem à crítica de Nietzsche ao hegelianismo, porém, entendemos aqui que a crítica de Nietzsche ao historicismo não se limita aos pontos supracitados por ambos autores. Por exemplo, a Escola Histórica Prussiana, de maneira geral, rejeitava a filosofia da história de $\mathrm{Hegel}^{6}$, que vê a história como universal, como apontamos mais acima, e ainda assim seus membros eram criticados por Nietzsche. Além do mais, os intelectuais do século XIX não se identificavam como historicistas, e, se considerarmos as críticas de Nietzsche a "historicistas", conforme temos insistido, seu grande alvo seria Ranke e suas idéias, e não o movimento como um todo.

$\mathrm{Na}$ trajetória de Nietzsche, percebe-se o quanto ele estava plenamente inserido nas discussões historiográficas de seu tempo, uma vez que não só leu uma série de historiadores de sua contemporaneidade, como Mommsen, Niebuhr, Droysen, Burckhardt, Grote, Gibbon, Sybel, Ranke, Brochard, Buckle, Carlyle, Gervinus, Herder, Lobeck, Michelet e Treitschke, mas também clássicos como Heródoto, Xenofonte, Tácito, Políbio, Lívio e Tucídides. Chegou a se corresponder com Taine, a quem enviou suas obras, e estudou no mesmo gymnasium que Ranke (BROBJER, 2004, p. 312-313), alvo de suas críticas.

Os estados alemães do século XIX, em especial a Prússia, estavam intensamente interessados pelo conceito de história. A Unificação da Alemanha (1871) levou os intelectuais a reflexões sobre qual história seria construída. Nietzsche estava imerso neste debate, mas é importante compreender que suas reflexões sobre a história se modificam ao longo de sua vida. Frente à complexidade do historicismo, como seu caráter multifacetado e as vinculações de Nietzsche com este movimento, pode-se analisar como o conceito de história está presente nos quatro fragmentos póstumos de seu primeiro período, que é o que fazemos a seguir.

\section{Reflexões de Nietzsche acerca do conceito de História}

Há alguns estudos no Brasil sobre a relação de Nietzsche com a História. No entanto, seus autores priorizaram a Segunda Consideração Intempestiva (BARROS, 2010, CALDAS, 2006). Nesta obra, Nietzsche apresentou algumas de suas idéias acerca da história posicionandose, inclusive, sobre questões como lembrança e esquecimento, ele também enunciou as três formas pelas quais ele entende a história - a história monumental, a história antiquária e história crítica -, discutiu conceitos como a-historico, sentido histórico e suprahistórico ${ }^{7}$. Talvez por causa destas abordagens específicas a obra seja frequentemente mencionada. $O$ renomado estudioso sueco Thomas H. Brobjer, no entanto, identifica que Nietzsche deixa de recorrer aos conceitos

\footnotetext{
${ }^{6}$ Também vemos como problemática a redução do pensamento de Hegel a sua filosofia da história, pois esse filósofo complexo passou por várias transformações em seu pensamento ao longo de sua vida. Para mais informações conferir: Grespan (2002).

${ }^{7}$ Os conceitos em itálico são respectivamente traduzidos por: erinnert, vergessen, monumentalische Historie, antiquarische Historie, kritische Historie, Unhistorische, historische Sinn e Überhistorisch.
} 
desenvolvidos nesta obra em momentos posteriores de sua trajetória. Segundo Brobjer, após 1874, Nietzsche parece não utilizar mais até mesmo "os importantes conceitos história monumental, história antiquária e história crítica ou suprahistórico" (BROBJER, 2004, p. 310-311) tanto que somente em quatro ocasiões isso acontece nas obras de Nietzsche posteriores a este período.

Brobjer, em Nietzsche's View of Value of Historical Studies and Methods, diz que a Segunda Intempestiva, pertencente ao início da produção intelectual de Nietzsche, "não é representativa da visão geral de Nietzsche sobre a história e os estudos e métodos históricos eram muito mais importantes para ele do que tem sido reconhecido" (BROBJER, 2004, p.321) ${ }^{9}$.

Quando analisamos as interpretações de Nietzsche sobre a história é importante observar que desde muito cedo ele se importava com a questão da objetividade da história. Em um fragmento do ano de 1871, o filósofo já tecia críticas persistentes, como podemos observar abaixo:

[...] É precisamente à nossa época, que se dá o título de historiadora "objetiva" e sem preconceitos, que eu quero proclamar que essa "objetividade" é somente um devaneio e que logo esta maneira de escrever a história - na medida em que não queira ser uma seca coleção de documentos - não terá outra significação senão a de ser uma coleção de exemplos que servem como princípios filosóficos universais do valor, dos quais a coleção de exemplos depende para ter um crédito duradouro ou totalmente efêmero [...]. Somente um pensador sério e independente, desligado de qualquer vã cobiça, percebe na história algo que merece ser dito: é somente nos olhos desprovidos de desejo do filósofo que a história reflete leis eternas, enquanto que o homem, mergulhado na corrente da vontade egoísta, quando possui razões para colocar a máscara da objetividade, deve se decidir a roer com uma diligência chocante o catálogo dos acontecimentos e até a sua casca mais aparente: ela revela com isso, com um julgamento que extrapola, o seu senso filosófico grosseiro, incapaz de alcançar uma compreensão mais profunda de si, e portanto indiferente [...] (NIETZSCHE, 2005, p.290 $)^{10}$

\footnotetext{
${ }^{8}$ Adaptação nossa de: "Nietzsche seems never again after 1874 to use the important concepts monumental, antiquarian, and critical history, or overhistorical.

${ }^{9}$ Tradução nossa de: “On the Uses and Disadvantages of History for life is not representative of Nietzsche's views of history generally, and that historical studies and methods were much more important to him than has been recognized."

${ }^{10} \mathrm{Em}$ alemão: [...] Gerade unserer Zeit, mit ihrer sich „objektiv“, ja voraussetzungslos gebärdenden Geschichtsschreibung, möchte ich zurufen, daß diese „Objektivität“ nur erträumt ist, daß vielmehr auch jene Geschichtsschreibung — soweit sie nicht trockene Urkundensammlung ist - nichts als eine Beispielsammlung für allgemeine philosophische Sätze zu bedeuten hat, von deren Werth es abhängt, ob die Beispielsammlung dauernde oder höchst zeitweilige Geltung verdient. [...]Nur der ernste und selbstgenugsame, allen eiteln Begehrungen enthobene Denker sieht etwas in der Geschichte, was der Rede werth ist: nur für die begierdelosen Augen des Philosophen spiegelt die Geschichte ewige Gesetze wieder, während der mitten im Strome des egoistischen Willens stehende Mensch, wenn er Gründe hat die Maske der Objektivität vorzunehmen, sich bescheiden muß, die Nomenklatur der Ereignisse, gleichsam ihre äußerste Rinde mit beleidigender Gründlichkeit zu benagen: wohingegen er sofort mit jedem erweiterten Urtheile, das er macht, seinen philosophisch rohen, tieferer Weltbetrachtung unzugänglichen und deshalb gleichgültigen Allerweltsverstand bloßstellt. eKGWB/NF-1871,9[42] — Nachgelassene Fragmente 1871. Disponível em: http://
} 
Este fragmento foi escrito exatamente no ano em que aconteceu a unificação da Alemanha. Assim, é provável que tenha sido elaborado até mesmo como uma crítica a este acontecimento. Uma pretensa objetividade da história, tão ambicionada pelos historicistas, é caracterizada por ele como um devaneio. Uma história feita desta maneira não seria mais do que uma "coleção de exemplos", o que, de acordo com suas percepções, é algo a se evitar. A crítica de Nietzsche parece ter como alvo uma história de caráter acumulativo e universalizante. $O$ fragmento mostra que estas coleções de exemplos "servem como princípios filosóficos universais do valor", portanto, nada objetiva, mas sim pretenciosa e egoísta.

Quando afirma que "logo esta maneira de escrever a história”, a objetiva, "não terá outra significação senão a de ser uma coleção de exemplos", Nietzsche fez uma "previsão" que não se confirmou plenamente. Apesar de ressignificada, criticada, readaptada e reinventada, a história se erigiu significativamente- Em realidade, a crítica de Nietzsche acabou contribuindo para a configuração da Geschichtswissenschaft (Ciência da História). Igualmente, as abordagens desenvolvidas no seio da escola prussiana constituíram-se em fundamento para uma interpretação histórica metodologicamente controlada.

A teoria da história, bem como a metodologia da história e a história da historiografia, atualmente, assumem a relação com o documento como um pressuposto. Sabem também que nenhuma objetividade será totalmente atingida em sua forma de conhecer. Este princípio é pedra angular na epistemologia da área. Mesmo que os historiadores tenham entendido e aceito parte das críticas de Nietzsche à objetividade, esta jamais deixará de ser cotejada pela comunidade dos historiadores profissionais, ainda que não seja totalmente alcançável. Estevão Martins (2009, p. 24) aponta, por exemplo, "sete requisitos de verossimilhança razoáveis e universais", capazes de garantir que o conhecimento histórico seja científico e metodologicamente controlável. Para Martins, trata-se de uma Geschichtswissenschaft sustentada na noção de "verdade com certeza provável" (MARTINS, 2009, p.24) conforme já apontado. Mesmo que apresentada em forma de narrativa, isso não exclui a possibilidade de ser ciência, pois narrativa não exclui cientificidade (COSTA LIMA, 1989).

Nem com os filósofos Nietzsche parece ter clemência. Seu tom irônico faz o filósofo ver "leis eternas" para a história, possivelmente aludindo às filosofias da história de Hegel ou de Marx. Isso se confirma também no fragmento datado de 1973, em que Nietzsche se mostra incrédulo com as leis históricas.

Certos autores sujeitaram o discurso histórico à noção de leis gerais, acreditando que com estas "é possível explicar um evento individual no sentido de se levarem em linha de conta todas as suas características por meio de hipóteses universais" (HEMPEL, 1995, P.424). Porém, no desenvolvimento da historiografia, tal noção perde forças e recebe críticas, como as de Nietzsche:

www.nietzschesource.org/\#eKGWB/NF-1871,9[42]. Acesso em: 25 maio 2015. 
A estatística prova que existem leis na história. Ela prova inclusive a vulgar e repugnante uniformidade da massa. Por que não vão praticar estatística em Atenas?! Quanto mais a massa é vil e indiferenciada, mais a lei estatística é rigorosa. [...] Abandonem toda a esperança, vocês que procuram aqui uma lei! Assim, ainda que existam leis na história, elas não tem nenhum valor, não mais do que a própria história, quer dizer, aquilo que aconteceu. Além disso, o que significa então o termo "leis"? Designam elas algo que se assemelhe de algum modo a uma lei da natureza ou à lei de um código? Porém a "lei" histórica não diz: "vocês devem", mas "foi assim". Ela é somente a expressão de um estúpido dado de fato, a propósito do qual ninguém pode mais perguntar "por quê?" "Aqui são concluídos em torno de 40 casamentos por ano" - Por que então 40 e não 80? - "Acredita-se que é assim e não de outra maneira!" - Muito instrutivo! Nós agradecemos. [...] (NIETZSCHE, 2005, p.292)11.

Defensor da filosofia pré-socrática, Nietzsche vê a vida como transitoriedade. Ele critica a ideia de que na história há imutabilidades. Ao citar a "estatística", ele a diferencia da lei natural e da lei jurídica. O que a História tem é apenas um dado de fato que não admite prever nem obrigar juridicamente. Ao questionar-se sobre qual tipo de lei seria a lei presente na "história", afirma que esta é somente um "estúpido dado" inquestionável.

Neste fragmento, ele também se mostra extremamente contra a tentativa de utilizar leis na natureza no discurso das ciências humanas. Porém, até que ponto Nietzsche estaria familiarizado com as discussões de Dilthey quando este separa as Geistwissenchaften (Ciências do Espírito, ou Ciências Humanas) das Naturwissenchaften (Ciências da Natureza). Pesquisando na página Nietzsche Source, por exemplo, encontramos referências de Nietzsche apenas às ciências da natureza, sem menção, em alemão, às ciências humanas, no sentido proposto por Dilthey.

Ainda sobre o fragmento, Nietzsche diz que há fatos que já foram e a estatística e a história quantitativa apresentam dados sem crítica e discussão. Problematizar e historicizar estas formas metodológicas, conforme Nietzsche fez, são procedimentos presentes no discurso historiográfico até os dias atuais. Boa parte do que Nietzsche criticava acabou, embora de forma ressignificada, sendo incorporado pela Ciência da História. Sabe-se que dados e fatos são problemáticos, para isso, desenvolveu-se toda uma ciência narrativa ao estilo de Rüsen, e manteve-se a necessidade de prova documental, sem a qual nenhum conhecimento histórico é possível, afinal, a história faz-se com documentos (MARROU, 1978).

\footnotetext{
${ }^{11} \mathrm{Em}$ alemão: „Die <Statistik beweist dass es Gesetze in der Geschichte> giebt. Ja, sie beweist, wie gemein und ekelhaft uniform die Masse ist. Ihr hättet einmal in Athen Statistik treiben sollen! Da würdet ihr den Unterschied gefühlt haben! Je niedriger und unindividueller eine Masse ist, um so strenger das statistische Gesetz. [] Überdies: was heisst denn hier "Gesetze"? Stehen sie irgendwie gleich einem Naturgesetz oder einem Rechtsgesetz? Es sagt doch nicht "ihr sollt", sondern „leider war es so“. Es ist der Ausdruck eines dummen faktischen Verhältnisses, bei dem Niemand mehr nach dem Warum? fragen darf. "Hier werden jährlich c. 40 Ehen geschlossen“ - Warum denn so viel und nicht 80?. Es ist nun einmal nicht anders"! - Sehr belehrend! Wir danken. eKGWB/NF-1873,29[41] - Nachgelassene Fragmente Sommer-Herbst 1873. Disponível em: http://www.nietzschesource. org/\#eKGWB/NF-1873,29[41]. Acesso em: 25 maio 2015.
} 
Nietzsche também fez de Leopold von Ranke alvo de suas críticas. Dentre os trinta e quatro fragmentos presentes na secção dedicada ao tema da objetividade e da cientificidade da história presentes nos Escritos sobre História, três aludiam a Ranke. Assim, Nietzsche se converteu em um dos principais críticos ao caráter objetivo da escrita rankeana. Isso é algo perfeitamente compreensível, tendo em vista os posicionamentos que pudemos perceber de Nietzsche a partir dos fragmentos já mencionados. Nietzsche realizava julgamentos sobre Ranke e sua obra tanto em seus escritos iniciais, quanto nos finais. Em um fragmento de sua primeira fase Nietzsche (2005, p. 295-296) escreveu que:

Quando historiadores como Ranke se elevam ao plano da generalidade, eles não transmitem nada: estes princípios nos eram já conhecidos bem antes de suas obras; isto lembra o absurdo desregramento das experiências com as quais se alegrava Zöllner nas ciências da natureza. ${ }^{12}$

Nietzsche não se refere somente a Ranke neste fragmento. A generalidade da expressão "historiadores como Ranke", certamente exclui seu amigo francês Taine, mas é plausível interpretar que Nietzsche se referia aos historiadores que enviaram artigos para a Historische Zeitschrift ou a algum de seus participantes mais ativos, dentre os quais Droysen e o próprio Ranke.

Se restam dúvidas sobre quem seriam estes "outros historiadores", Nietzsche identifica Ranke como um alvo para suas críticas acerca de como a história deveria ou não ser conduzida e como este tipo de reflexão poderia ser útil para os debates importantes em sua época. Assim, as principais críticas com relação à pretensão de objetividade dos historiadores são dirigidas direta, mas não exclusivamente, a Ranke.

Quando Nietzsche se refere ao "plano da generalidade", dizendo que por este os historiadores "não transmitem nada", aparece a mesma crítica sobre leis/principios pelos quais "acreditase que é assim e não de outra maneira!", do fragmento anteriormente analisado. Johann Carl Friedrich Zöllner, o outro nome citado, era professor em Leipzig, onde Nietzsche também estudou. A menção a Zöllner acontece, provavelmente, porque este físico tecia inúmeras críticas à forma como seus pares faziam ciência, sendo, inclusive, mal-visto em seu próprio campo, por seu "absurdo desregramento das experiências".

Ainda em 1873 Nietzsche contrapôs a história à arte, mais especificamente à dramaturgia:

A "objetividade" do historiador é um absurdo. Isto significa que um acontecimento pode ser examinado de maneira tão límpida nos seus motivos e nas suas consequências, que não produziria nenhum efeito e continuaria sendo

\footnotetext{
${ }^{12} \mathrm{Em}$ alemão: Wenn solche Historiker wie Ranke allgemein werden, belehren sie nicht: solche Sätze wusste man längst vor ihrer Arbeit: sie erinnern an das unsinnige Experimentiren, über das Zöllner in den Naturwissenschaften klagt. eKGWB/NF1873,29[92] - Nachgelassene Fragmente Sommer-Herbst 1873Disponível em: http://www.nietzschesource.org/\#eKGWB/ NF-1873,29[92]. Acesso em: 25 maio 2015.
} 
um processo puramente intelectual [...] Pensar objetivamente a história, este é o trabalho secreto do dramaturgo: tudo reunir pelo pensamento, ligar qualquer acontecimento particular ao conjunto da teia, baseando-se na hipótese que não tem qualquer base empírica nem histórica e que contradiz qualquer "objetividade", tal como ela é compreendida habitualmente. É o instinto artístico, não o instinto de verdade, que impulsiona o homem a estender a sua teia sobre o passado e se tornar senhor dele. A forma acabada de uma tal historiografia é pura obra de arte: sem qualquer traço da verdade comum.[...] (NIETZSCHE, 2005, p.296-297) $)^{13}$

O fragmento mostra a mordaz crítica de Nietzsche à pretensa objetividade dos historiadores. Sua analogia do historiador e do dramaturgo, além de reforçar sua oposição à objetividade "científica" nas ciências humanas em geral, e na história em particular, revela outra caracteística marcante de seu pensamento. A inteligência humana, para ele, é criadora. A arte mostra de modo mais evidente o caráter criador, transbordante, da inteligência humana. Ironicamente ela mostra que é mais honesto o dramaturgo, que busca "ligar qualquer acontecimento particular ao conjunto da teia, baseando-se na hipótese que não tem qualquer base empírica nem histórica" a título de arte, ou seja, não há pretensão científica nessa narrativa. Os escritos deste seguem o "instinto artístico", escrevendo sem a pretensão de um "instinto de verdade". Assim, o dramaturgo escreveria sua obra com um entendimento plural do termo, e não uma "verdade comum" e inquestionável, estabelecida para um grande número de pessoas, algo que, segundo Nietzsche, os historiadores fazem.

\section{Considerações Finais}

Os intelectuais considerados historicistas, apesar de estarem inseridos em uma gama de discussões e de manifestarem uma pluralidade de pensamentos, tinham em comum o fato de estarem intensamente envolvidos com a política. Aliado a estas questões, o historicismo começou a preocupar-se com reflexões sobre o método histórico, de como as fontes deveriam ser analisadas, de sua comprobabilidade, cientificidade e objetividade. Avesso a esta história vinculada à política, Nietzsche defendeu uma história que estava vinculada à cultura.

O objetivo deste artigo foi ampliar a discussão acerca do modo como aparece a percepção de Nietzsche sobre a história em sua primeira fase a partir da análise de fragmentos póstumos.

\footnotetext{
${ }^{13}$ Em alemão: „Objectivität des Historikers" ist ein Unsinn. Man meint, es bedeute, dass ein Ereigniss in allen seinen Motiven und Folgen so rein angeschaut werde, dass es keine Wirkung mehr thut, nämlich ein reiner intellectueller Process bleibt [...] Objectiv Geschichte denken ist die stille Arbeit des Dramatikers: alles an einander denken, alles Vereinzelte zum Ganzen zu weben: überall mit der künstlerischen Voraussetzung, dass der Plan, der Zusammenhang darin sei: eine Voraussetzung, die gar nicht empirisch-historisch ist und aller „Objektivität“, wie man sie gewöhnlich versteht, widerstreitet. Dass der Mensch die Vergangenheit überspinnt und bändigt, ist Kunsttrieb: nicht Wahrheitstrieb. Die vollkommene Form einer solchen Geschichtsschreibung ist rein Kunstwerk: ohne einen Funken der gemeinen Wahrheit.[ ] eKGWB/NF-1873,29[96] - Nachgelassene Fragmente Sommer-Herbst 1873. Disponível em: http://www.nietzschesource.org/\#eKGWB/NF1873,29[96]. Acesso em: 25 maio 2015.
} 
Segundo se pode evidenciar na análise, a forma de Nietzsche compreender a história ultrapassa o que se encontra em sua Segunda Consideração Intempestiva, tão estudada pela historiografia brasileira, mas que não consegue, por si só, abarcar em profundidade o raciocínio do filósofo acerca da história.

As análises do artigo permitem quatro considerações acerca do pensamento de Nietzsche. A primeira é que a objetividade e a cientificidade da história são extemamente importantes para se entender quais os posicionamentos de Nietzsche acerca desta temática. E que, sempre que o filósofo se refere a ambos os conceitos, ao menos nos fragmentos analisados, os trata de forma depreciativa.

A segunda é que Nietzsche mantém intenso diálogo com os intelectuais de seu tempo. Portanto, talvez não seja verdadeira a tese de que ele era um intelectual que nasceu póstumo. Suas discussões sobre as ultilidades e desvantagens da história para a vida estão vinculadas à discussões referentes a Prússia que, depois, será a Alemanha unificada. Ou seja, a afirmação de que Nietzsche "estava a frente de seu tempo" ou que "antecipou" qualquer coisa é um argumento questionável do ponto de vista historiográfico.

Em terceiro lugar, deprende-se que as críticas de Nietzsche a Ranke e seus pares devese ao modo como entendia a história, avessa à dos historiadores da Historische Zeitschrift e, possivelmente, outros historiadores prussianos que defendiam a história como ciência. Nietzsche defendia uma Historie für das Leben, ou seja, uma história que tem como base aspectos culturais, com valores que enfatizam a vida. Estes seriam os aspectos úteis e importantes para a construção da nação alemã, de acordo com a opinião do filósofo. Assim, mesmo que a pretenção de Nietzsche fosse que os historiados tivessem o olhar desvinculado da política, como os filósofos, sua própria atitude sugere que ele também tinha um posicionamento político acerca do lugar em que vivia e que a história poderia ter ou não utilidade se fosse compreendida da forma como ele aponta.

Por último, ele é um dos intelectuais prussianos mais influentes e importantes para a filosofia na segunda metade do século XIX. Talvez nao tenha conseguido perceber que boa parte daquilo que criticava era a gênese de uma nova epistemologia, naquele momento ainda em configuração, do que hoje denomina-se Ciência da História, Geschichtswissenschaft, em língua alemã. Desta forma, esta questão da objetividade e da cientificidade da história, ainda que resignificada, principalmente devido às críticas de Nietzsche, acompanha o discurso historiográfico até os dias atuais.

\section{Referências}

ABBEY, Ruth. Introduction. In: _ _ _ _ _. Nietzsche's Middle Period. Madison Avenue, New York: Oxford University Press, Inc., 2000. 
BARROS, José D’Assunção. O Paradigma da Descontinuidade em Nietzsche uma análise da Primeira Parte da $2^{\mathrm{a}}$ Consideração Intempestiva de Nietzsche. Lusíada, Série de História, Lisboa, v. 7, p. 417-441, 2010.

BENTIVOGLIO, Julio. Cultura política e historiografia alemã no século XIX - a escola histórica prussiana e a Historische Zeitschrift. Revista de Teoria da História, Goiás, v.3, n.1, p.20-58, 2010.

BROBJER, Thomas. Nietzsche's View of Historical Studies and Methods. Journal of the History of Ideas, Baltimore, v. 65, n. 2, p. 301-322, apr. 2004.

CALDAS, Pedro Spinola Pereira. História, ação e cultura: um esboço de comparação entre Hegel e Nietzsche. Fênix, Uberlândia, v. 3, n. 2, p. 1-15, 2006.

COSTA LIMA, Luiz. A Aguarras do Tempo. Rio de Janeiro: Rocco, 1989.

ELIAS, Norbert. II. Uma Digressão sobre o Nacionalismo. In: Os alemães: a luta pelo poder e a evolução do habitus nos séculos XIX e XX. Tradução de Álvaro Cabral. Rio de Janeiro: Jorge Zahar Ed., 1997.

GIACÓIA JUNIOR, Oswaldo. Dados Biográficos. In: 2000.

GIACÓIA JUNIOR, Oswaldo. Nietzsche e a crítica do historicismo. In: MALERBA, Jurandir (org). Lições de história: da história cientifica à crítica da razão metódica no limiar do século XX. Porto Alegre: FGV: EDIPUCRS, 2013.

GRANIER, Jean. Capítulo I - A biografia. Nietzsche. Tradução: Denise Bottmann. Porto Alegre, RS: L\&PM, 2011.

GRESPAN, Jorge. Hegel e o Historicismo. História Revista (UFG), Goias, v. 7, p. 55-78, 2002.

HEMPEL, Carl G. A Função das Leis Gerais em História. In: Teorias da História. Tradução e prefácio de Vítor Matos e Sá. Lisboa: Fundação Calouste Gulbenkian, 1995.

KITCHEN, Martin. História da Alemanha moderna. São Paulo: Cultrix, 2013.

MARROU, Henri-Irenée. Sobre o conhecimento histórico. Rio de Janeiro: Zahar Editores, 1978.

MARTINS, Estevão Chaves Rezende. Historicismo: tese, legado, fragilidade. História Revista (UFG), Gioânia, v. 7, n. 1/2, p. 1-22, 2004.

MARTINS, Estevão Chaves Rezende. Veritas filia temporis? O conhecimento histórico e a distinção entre filosofia e teoria da história. Síntese, Belo Horizonte, v. 34, p. 5-25, 2009.

MARTON, Scarlett. Introdução. In: _ _ _ _. Nietzsche das forças cósmicas aos valores humanos. São Paulo: Brasiliense, 1990.

MARTON, Scarlett. Nietzsche e a arte de decifrar enigmas - Treze conferências europeias. São 
Paulo: Edições Loyola, 2014.

MARTON, Scarlett. Nietzsche: a transvaloração de valores. São Paulo: Moderna, 1993.

MATA, Sérgio da. Leopold von Ranke (1795-1886). In: MARTINS, Estevão de Rezende (org). $A$ história pensada. São Paulo: Contexto, 2010.

MATA, Sérgio da. Elogio do Historicismo. In: VARELLA, Flávia et al (Org.). A dinâmica do historicismo. Belo Horizonte: Argvmentvm, 2008.

NIETZSCHE, Friedrich. Escritos sobre história. Apresentação, tradução e notas: Noeli Correia de Melo Sobrinho. Rio de Janeiro: Ed. PUC-Rio; São Paulo: Loyola, 2005.

NIETZSCHE, Friedrich. Segunda consideração intempestiva: da utilidade e desvantagem da história para a vida. Tradução de Marco Antônio Casanova. Rio de Janeiro: Relume Dumará, 2003.

NIETZSCHE SOURCE. Disponível em: <http://www.nietzschesource.org/ documentation/en/ eKGWB.html>. Acesso em: 20 set. 2016.

PASCHOAL, Antonio Edmilson. A Genealogia de Nietzsche. Curitiba: Champagnat, 2005.

RÜSEN, Jörn. Narratividade e objetividade nas ciências históricas. In.__ _ _ _ • Jörn Rüsen e o ensino de história. Organizadores Maria Auxiliadora Schmidt, Isabel Barca, Estevão Rezende Martins. Curitiba: Ed. UFPR, 2011.

SAFRANSKY, Rüdiger. Nietzsche, biografia de uma tragédia. Tradução Lya Lett Luft. São Paulo: Geração Editorial, 2011.

SCHOLTZ, Gunter. O problema do historicismo e as ciências do espírito no século XX. História da Historiografia, Ouro Preto, n. 6, p. 42-63, 2011.

SCHOLTZ, Gunter. The phenomenon of 'historicism' as a backcloth of Biblical Scholarship. In.: MACHINIST, Peter; SKA, Jean Louis (Ed.). Hebrew Bible - Old Testament. The History of its interpretation. Göttingen: Vandenhoeck \& Ruprecht, 2013. p. 64-89.

WEHLING, Arno. A temática do historicismo. In: _ _ _ _. A invenção da história: estudos sobre o historicismo. Rio de Janeiro, Editoria Central da Universidade Gama Filho; Niterói, Editora da Universidade Federal Fluminense, 1994. Cap. 1. 